\title{
Gastric Necrosis and Perforation Following Massive Gastric Dilatation in an Adolescent Girl: A Rare Cause of Acute Abdomen
}

\author{
Zlatan Zvizdic ${ }^{1 *}$, Asmir Jonuzi ${ }^{1}$, Aleksandra Djuran ${ }^{2}$ and Semir Vranic ${ }^{3 *}$ \\ ${ }^{1}$ Clinic of Pediatric Surgery, University Clinical Center Sarajevo, Sarajevo, Bosnia and Herzegovina, ${ }^{2}$ Department of \\ Pathology, University Clinical Center Sarajevo, Sarajevo, Bosnia and Herzegovina, ${ }^{3}$ College of Medicine, Qatar University, \\ Doha, Qatar
}

Gastric necrosis with perforation is a rare and potentially life-threatening condition in childhood beyond the neonatal period. We report a case of gastric necrosis and perforation of a portion of the great curvature due to a massive gastric dilatation caused by pathological aerophagia in a 13-years-old, mentally impaired adolescent girl.

OPEN ACCESS

Edited by:

Francesco Morini,

Bambino Gesù Children Hospital

(IRCCS), Italy

Reviewed by:

Roberto Tambucci,

Catholic University of Louvain,

Belgium

Sanja Miodrag Sindjic Antunovic

University of Belgrade, Serbia

*Correspondence:

Zlatan Zvizdic

zlatan.zvizdic@gmail.com

Semir Vranic

svranic@qu.edu.qa;

semir.vranic@gmail.com

Specialty section

This article was submitted to

Pediatric Surgery,

a section of the journal

Frontiers in Surgery

Received: 11 November 2018

Accepted: 14 January 2019

Published: 30 January 2019

Citation:

Zvizdic Z, Jonuzi A, Djuran A and Vranic $S$ (2019) Gastric Necrosis and Perforation Following Massive Gastric Dilatation in an Adolescent Girl: A Rare

Cause of Acute Abdomen.

Front. Surg. 6:3.

doi: 10.3389/fsurg.2019.00003
Despite the successful surgical treatment, the patient's condition rapidly deteriorated post-operatively and she died due to the multisystem organ failure and multiple infections. In addition, we surveyed the literature on this rare condition and assessed the preventive actions to reduce this life-treating condition.

Keywords: gastric dilatation, necrosis, gastric perforation, pathological aerophagia, acute abdomen

\section{INTRODUCTION}

The stomach is a well-vascularized organ that receives a blood supply from the left gastric artery (a branch of celiac axis), the right gastric artery (a branch of the common hepatic artery), the right gastroepiploic artery (a branch of the gastroduodenal artery), the left gastroepiploic artery (a branch of the splenic artery), and the short gastric arteries, which also arise from the splenic artery. Therefore, gastric infarction is uncommon compared with other parts of the gastrointestinal tract. The reported causes of gastric infarction are diverse and include gastric volvulus (1), intrathoracic herniation (2), ingestion of caustic substances (3), complications after gastric surgery (4), arterial occlusion by embolus or thrombus (5), acute necrotizing gastritis (6), and massive gastric dilatation related to excessive food intake due to psychogenic polyphagia, pathologic aerophagia (PA), bulimia nervosa, and Prader-Willi syndrome (7-10).

Aerophagia, as one of the risk factors of gastric ischemia, represents a rare functional gastrointestinal disorder characterized by excessive and inappropriate swallowing of air resulting in progressive abdominal distension. The prevalence of aerophagia in children is estimated to be $7.5 \%$ (range $0.1-8.8 \%)(11-14)$. Although the disease is predominantly seen in healthy children exposed to stressful situations, $25 \%$ of the cases affects the children with severe psychiatric and/or neurological disorders (8). Aerophagia is usually short-term, but can become chronic in rare cases. If so, it can be associated with various gastrointestinal symptoms, such as abdominal pain, flatulence and belching when it is described as a pathologic aerophagia (PA) (15). In extreme cases, PA may progress to massive gastric and intestinal distension with the consequent development of ileus, volvulus, necrosis or perforation $(16,17)$. PA may induce the atony and hypotony of the alimentary tract, which in conjunction with chronic distension of the mucosa and smooth muscles of the gut, may lead to gastric or intestinal ischemia and consequent necrosis and perforation (17). 


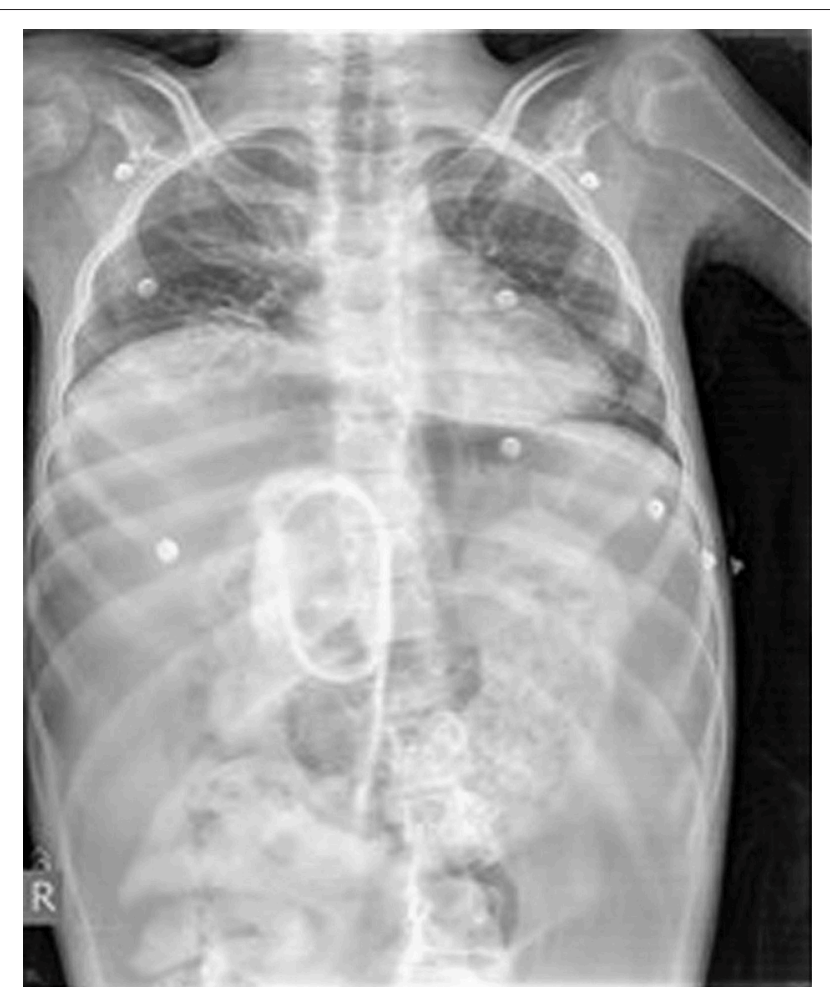

FIGURE 1 | A plain abdominal radiograph showing a massive pneumoperitoneum within the abdominal cavity.

We report here a case of gastric necrosis and perforation due to massive gastric dilatation caused by PA in a 13-years-old mentally impaired girl. We also surveyed the literature on this rare condition and discussed the preventive actions that could hamper the fatal outcome.

\section{CASE REPORT}

A 13-years-old mentally impaired girl (since birth due to perinatal asphyxia) presented to the emergency department (ED) with a severe abdominal pain and signs of acute abdomen, fever, and hypovolemic shock. She was unconscious, febrile, with a blood pressure of $80 / 40 \mathrm{mmHg}$, pulse rate of $160 / \mathrm{min}$, and a respiratory rate of $34 / \mathrm{min}$. Physical examination revealed a diffuse tenderness and a muscular rigidity. The abdomen was distended and bowel sounds were absent. The abdominal Xray obtained in a supine position showed a massive free air within the peritoneal cavity and undigested remains of food along the alimentary tract imitating the contrasting liquid (Figure 1). At hospital admission, a medical audit accompanying the girl described a 4-days history of food rejection, frequent vomiting and progressive deterioration of her general condition. Her anamnesis was negative for traumatic events but was suggestive for PA due to a characteristic appearance of air swelling and abdominal distension that rapidly progressed during the day and caused the flatus during sleep.

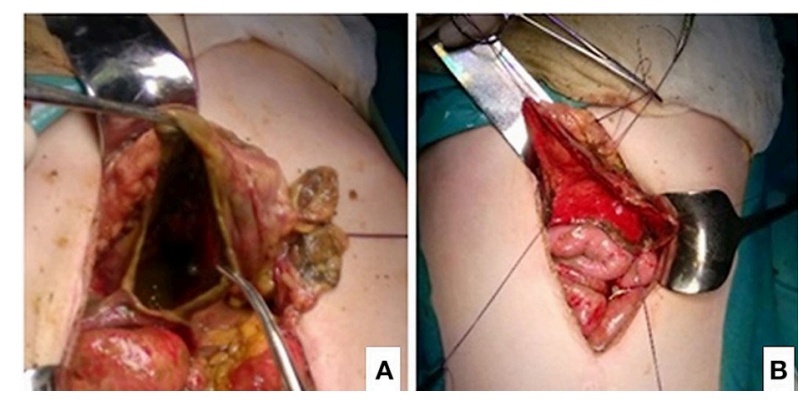

FIGURE 2 | (A,B) Intraoperative findings of partial gastric necrosis and perforation (before and after debridement of necrotic tissue).

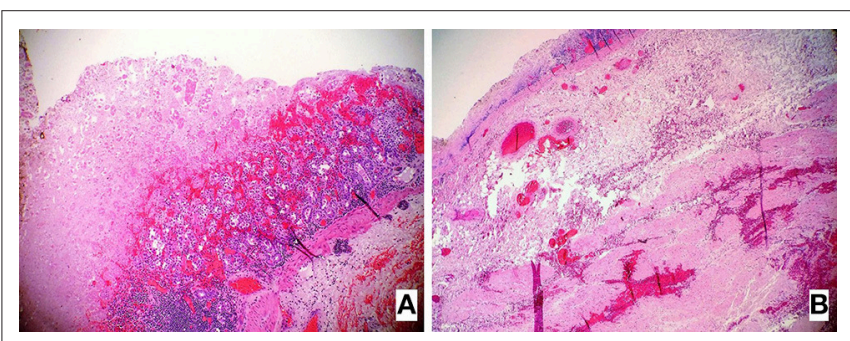

FIGURE 3 | (A,B) Hematoxylin and Eosin-stained (H\&E) sections of the resected stomach revealed the presence of the extensive necrosis affecting the entire gastric wall $\mathbf{( B )}$ while the left image $(\mathbf{A})$ shows in part preserved the mucosal surface of the gastric wall $(10 \times)$.

Laboratory investigations revealed the following results: White blood cell count: 7.100/uL; mean platelet volume: 11.8 $\mathrm{fL}$; platelet count: $220 \times 10^{3} / \mathrm{uL}$; hemoglobin: $11.1 \mathrm{~g} / \mathrm{dL}$; hematocrit: $35.2 \%$; serum proteins: $5.7 \mathrm{~g} / \mathrm{dL}$; serum albumin: 2.9 g/dL; serum globulin: $2.8 \mathrm{~g} / \mathrm{dL}$; aspartate aminotransferase: 107 IU/L; alanine aminotransferase: $30 \mathrm{IU} / \mathrm{l}$; creatinine: $0.9 \mathrm{mg} / \mathrm{dl}$; serum sodium: $135 \mathrm{mEq} / \mathrm{L}$; serum potassium: $5.4 \mathrm{mEq} / \mathrm{L}$; serum chloride: $101 \mathrm{mEq} / \mathrm{L}$; C-reactive protein: $367.4 \mathrm{mg} / \mathrm{L}$; serum lactate dehydrogenase: $401 \mathrm{IU} / \mathrm{L}$; serum creatine kinase: 4,086 IU/L; serum glucose: $107 \mathrm{mg} / \mathrm{dL}$; arterial blood $\mathrm{pH}$ : $7.07 \mathrm{nmol} / \mathrm{L}$; $\mathrm{PaCO}_{2}: 4.93 \mathrm{kPa} ; \mathrm{pO}_{2}: 5.59 \mathrm{kPa} ; \mathrm{HCO}_{3}: 10.5 \mathrm{mmol} / \mathrm{L}$; base excess: $18.8 \mathrm{mEq} / \mathrm{L}$.

Following an aggressive resuscitation with intravenous hydration, decompression of the stomach, a correction of metabolic abnormalities, and administration of empiric antibiotic therapy (amikacin, metronidazole, and meropenem), an emergency laparotomy was performed. It revealed a massively distended and partially necrotic stomach. Huge amounts of free peritoneal fluid (about four liters) with food particles due to perforation of the necrotic gastric wall were removed. The size of the perforation measured $7 \times 3 \mathrm{~cm}$ affecting the greater curvature on the posterior wall of the stomach (Figures 2A,B).

A free peritoneal fluid with food particles was washed out from the abdominal cavity. The gastric perforation was treated by debridement of necrotic tissue and a primary closure with additional using an omental patch. The debrided necrotic gastric 
tissue was submitted to the pathologist for the examination. The pathology assessment of the gastric wall showed a multiple areas of massive, transmural necrosis (Figures 3A,B).

Post-operatively, the patient was transferred to the pediatric intensive care unit (PICU) on mechanical ventilation and treated with inotropes, cefotaxime, metronidazole, gentamicin, and fluconazole. A fourth day of admission, abdominal cultures taken at the laparotomy as well as a blood culture showed Enterococcus faecalis and Candida glabrata infections.

In the following days, despite an extensive medical support, her clinical condition rapidly deteriorated and she eventually died on day 26 after admission due to overwhelming infections and progressive multisystem failure.

\section{DISCUSSION}

A gastric dilatation is a life-threating condition that may arise develop as a consequence of PA characterized by an excessive and inappropriate swallowing of air, especially in the mentally impaired persons (8). The resulting gastric dilatation may lead to a stomach necrosis and perforation. Aerophagia in association with mental illnesses constitutes $25 \%$ of all PA cases, particularly in patients with mental impairment, autism, and Rett syndrome (18). According to the Rome criteria, the diagnosis of PA is established in cases where abdominal distension and/or repetitive flatulence/belching, caused by air swallowing, presents for more than 12 weeks in a year (19). Gastric necrosis with perforation caused by a gastric dilatation is an extremely rare complication. According to some authors, gastric perforation occurs more frequently on the lesser curvature due to its reduced elasticity coefficient as well as its greater stretching compared with other parts of the stomach (20). In contrast, in the present case, gastric perforation affected the greater curvature. Patients with an acute gastric perforation require immediate resuscitation due to the third-space loss, and an immediate laparotomy is usually required. A surgical repair should be preceded by basic radiological procedures, such as an abdominal radiograph that would reveal a pneumoperitoneum, and an oral contrast application that would show an extravasation with a gastric wall irregularity or disruption (21). In children, gastric defects can usually be repaired with a simple closure, thus avoiding potential feeding difficulties seen after sleeve gastrectomy (22). We have applied such a procedure of simple suturing after the debridement of the surrounded thinned gastric wall. Unfortunately, after post-operative stabilization of the patient and a successful repair of the gastric defect proven by oral contrast, her clinical condition rapidly deteriorated and she died on day 26 after admission due to overwhelming infections and progressive multisystem failure. Gastric necrosis and perforation usually have a poor outcome with a recorded mortality rate of $50-80 \%$ particularly in cases of delayed diagnosis and treatment (23). In our case, the patient was admitted to the ED with signs of advanced peritonitis accompanied by metabolic disturbances, such as severe metabolic acidosis and hypotonic dehydration. A timely recognition of disturbed clinical condition, altered vital signs and laboratory findings suggestive of gastric perforation could have led to early hospital admission and prompt treatment that could save the patient.

The current preventive options of healthy children with PA consist of educating both the children and their parents and avoiding precipitating factors, such as drinking straws, carbonated drinks, and chewing gum. Psychotherapy may be particularly useful in children with associated psychological disorders. However, such approaches may not be suitable for children with severe mental impairment. Lee et al. (24) suggested the placement of a percutaneous endoscopic gastrostomy (PEG) to prevent massive and persistent bowel distention that could potentially result in surgical emergencies. Fukuzawa et al. (25) recently suggested a method of surgical bowel reconstruction (esophagogastric separation and abdominal esophagostomy via jejunal interposition) to solve the extreme forms of PA in the neurologically impaired children. None of these preventive measures (conservative or surgical) was undertaken in the presented case. We point out here that pediatric PA can be diagnostically challenging, especially in mentally impaired children due to the difficulties related to the clinical assessment (medical history and clinical examination).

In conclusion, this case shows the crucial importance of the preventive actions, early diagnosis and appropriate treatment of a gastric perforation caused by a PA. The preventive measures may be particularly challenging in mentally impaired children with PA as seen in our case. Nevertheless, the prevention of PA is worthy as it may hamper the potentially fatal consequences.

\section{ETHICS STATEMENT}

The study has been performed in accordance with the ethical standards laid down in the 1964 Declaration of Helsinki. The informed consent was obtained from the patient's family. The case report was shared with the local ethical committee; it is however the policy of this committee not to review case reports. The patient's parent gave the consent to include the data in the present case study.

\section{AUTHOR CONTRIBUTIONS}

ZZ and SV conceived the study. ZZ and AJ did the clinical exam and performed the surgery. $\mathrm{AD}$ and $\mathrm{SV}$ did the histopathological diagnostics. All authors wrote and approved the final version of the manuscript.

\section{FUNDING}

The publication of this article was funded by the Qatar National Library. 


\section{REFERENCES}

1. Trecroci I, Morabito G, Romano C, Salamone I. Gastric volvulus in childrena diagnostic problem: two case reports. J Med Case Rep. (2016) 10:138. doi: 10.1186/s13256-016-0934-3

2. Ito TE, Hasnie R, Crosby DL, Milbrandt JC, Ettema S, Duong M. Gastric volvulus complication in an infant with undiagnosed congenital diaphragmatic hernia presenting with acute respiratory distress. Pediatr Emerg Care (2012) 28:1078-80. doi: 10.1097/PEC.0b013e31826cedaf

3. Contini S, Scarpignato C. Caustic injury of the upper gastrointestinal tract: a comprehensive review. World J Gastroenterol. (2013) 19:3918-30. doi: 10.3748/wjg.v19.i25.3918

4. Do PH, Kang YS, Cahill P. Gastric infarction following gastric bypass surgery. J Radiol Case Rep. (2016) 10:16-22. doi: 10.3941/jrcr.v10i4.2280

5. Davoodabadi A, Talari HR, Jahanbakhsh M. Isolated common hepatic artery branch thrombosis: results and risk factors. Acta Med Iran. (2016) 54:610-3.

6. Mukhopadhyay M, Saha AK, Sarkar A, Tripathi SN, Biswas S, Mandal D, et al. Gastric gangrene due to necrotizing gastritis. Indian J Surg. (2011) 73:65-7. doi: 10.1007/s12262-010-0134-0

7. Heijneman JAM, Tahmassian R, Karsten T, van der Vorm ER, Meynaar IA. Gastric dilatation and perforation due to binge eating: a case report. Neth $J$ Crit Care (2013) 17:18-20.

8. de Jesus LE, Cestari AB, Filho OC, Fernandes MA, Firme LH. Pathologic aerophagia: a rare cause of chronic abdominal distension. Rev Paul Pediatr. (2015) 33:372-6. doi: 10.1016/j.rppede.2015.06.005

9. Patocskai EJ, Thomas JM. Gastric necrosis in a patient with bulimia. Eur J Surg. (2002) 168:302-4. doi: 10.1002/ejs.50

10. Stevenson DA, Heinemann J, Angulo M, Butler MG, Loker J, Rupe N, et al. Gastric rupture and necrosis in Prader-Willi syndrome. J Pediatr Gastroenterol Nutr. (2007) 45:272-4. doi: 10.1097/MPG.0b013e31805b82b5

11. Devanarayana NM, Rajindrajith S. Aerophagia among Sri Lankan schoolchildren: epidemiological patterns and symptom characteristics. J Pediatr Gastroenterol Nutr. (2012) 54:516-20. doi: 10.1097/MPG.0b013e318236051d

12. Loening-Baucke V. Aerophagia as cause of gaseous abdominal distention in a toddler. J Pediatr Gastroenterol Nutr. (2000) 31:204-7. doi: 10.1097/00005176-200008000-00026

13. Caplan A, Walker L, Rasquin A. Validation of the pediatric Rome II criteria for functional gastrointestinal disorders using the questionnaire on pediatric gastrointestinal symptoms. J Pediatr Gastroenterol Nutr. (2005) 41:305-16. doi: 10.1097/01.mpg.0000172749.71726.13

14. Lekkas CN, Lentino W. Symptom-producing interposition of the colon. Clinical syndrome in mentally deficient adults. JAMA (1978) 240:747-50. doi: 10.1001/jama.1978.03290080037020

15. Gauderer MW, Halpin TC Jr., Izant RJ Jr. Pathologic childhood aerophagia: a recognizable clinical entity. J Pediatr Surg. (1981) 16:301-5. doi: 10.1016/S0022-3468(81)80684-7
16. Hwang JB, Choi WJ, Kim JS, Lee SY, Jung CH, Lee YH, et al. Clinical features of pathologic childhood aerophagia: early recognition and essential diagnostic criteria. J Pediatr Gastroenterol Nutr. (2005) 41:612-6. doi: 10.1097/01.mpg.0000179856.68968.e0

17. van der Kolk MB, Bender MH, Goris RJ. Acute abdomen in mentally retarded patients: role of aerophagia. Report of nine cases. Eur J Surg. (1999) 165:50711. doi: 10.1080/110241599750006802

18. Lecine T, Michaud L, Gottrand F, Launay V, Faure C, Bonnevalle M, et al. Children who swallow air. Arch Pediatr. (1998) 5:1224-8. doi: 10.1016/S0929-693X(98)81240-2

19. Helgeland H, Flagstad G, Grotta J, Vandvik PO, Kristensen H, Markestad T. Diagnosing pediatric functional abdominal pain in children (415 years old) according to the Rome III Criteria: results from a Norwegian prospective study. J Pediatr Gastroenterol Nutr. (2009) 49:309-15. doi: 10.1097/MPG.0b013e31818de3ab

20. Akalonu A, Yasrebi M, Molle Rios Z. Spontaneous gastric perforation in two adolescents. Am J Case Rep. (2016) 17:694-8. doi: 10.12659/AJCR.898939

21. Lin CM, Lee HC, Kao HA, Hung HY, Hsu CH, Yeung CY, et al. Neonatal gastric perforation: report of 15 cases and review of the literature. Pediatr Neonatol. (2008) 49:65-70. doi: 10.1016/S1875-9572(08)60015-7

22. Libeer F, Vanhamel N, Huyghe M, Verlinden E. Spontaneous gastric rupture in non-neonatal children: a case report. Acta Chir Belg. (2007) 107:560-3. doi: 10.1080/00015458.2007.11680124

23. Casey KM, Quigley TM, Kozarek RA, Raker EJ. Lethal nature of ischemic gastropathy. Am J Surg. (1993) 165:646-9. doi: 10.1016/S0002-9610(05)80453-2

24. Lee EJ, Song AR, Choi E, Hwang JB, Oh HJ, Lee YH. A case of pathologic aerophagia with mental retardation managed by percutaneous endoscopic gastrostomy. Korean J Pediatr Gastroenterol Nutr. (2000) 3:93-7. doi: 10.5223/kjpgn.2000.3.1.93

25. Fukuzawa H, Urushihara N, Fukumoto K, Sugiyama A, Mitsunaga $\mathrm{M}$, Watanabe $\mathrm{K}$, et al. Esophagogastric separation and abdominal esophagostomy via jejunal interposition: a new operation for extreme forms of pathologic aerophagia. J Pediatr Surg. (2011) 46:2035-7. doi: 10.1016/j.jpedsurg.2011.05.024

Conflict of Interest Statement: The authors declare that the research was conducted in the absence of any commercial or financial relationships that could be construed as a potential conflict of interest.

Copyright (C) 2019 Zvizdic, Jonuzi, Djuran and Vranic. This is an open-access article distributed under the terms of the Creative Commons Attribution License (CC BY). The use, distribution or reproduction in other forums is permitted, provided the original author(s) and the copyright owner(s) are credited and that the original publication in this journal is cited, in accordance with accepted academic practice. No use, distribution or reproduction is permitted which does not comply with these terms. 